chemists for industry. Like Mr. Fleming, Mr. Rintoul laid a good deal of stress upon the training which supplements that given at the university. For the analyst, post-graduate training in general research or in chemical engineering, etc., is desirable. For the chemist in charge of plant, a two-year course in research or in chemical engineering might equally be desirable but it is highly important that this postgraduate training should be obtained in a university other than that in which he qualified, so as to widen his outlook as much as possible. On entering industry, a year or so should be given to analytical work.

Stressing the value of the knowledge acquired outside the university in such post-graduate work, Mr. Rintoul emphasised the continual necessity for the works chemist to keep himself in touch with developments by membership of scientific or industrial societies and attendance at their meetings. The suggestion of special leave for selected men for a vefresher course after five years' service or more was akin to suggestions made by Mr. Fleming. Equally for the research chemist, Mr. Rintoul urged that post-graduate training should be carried out in a fresh university on account of the wider technique and experience thus acquired, as well as the greater stimulus given to originality by a change of environment. The training of the chemist for definitely commercial work is probably best completed after entering industry itself.

In most of the papers and in the discussion, full attention was directed to the social aspects involved in planning technical education and particularly the problems raised by mechanisation. Apart, however, from a very demonstrable consciousness that technical education must be regarded as a vital national matter and not a purely local one or the concern of industries by themselves, the discussion made little definite contribution to immediate progress, and the valuable suggestions made from the industrial side scarcely attracted the attention they deserved. None the less, the discussion of this subject at a British Association meeting should at least assist the formulation of a definite and adequate policy in which technical education is treated not as a thing apart, but in relation to those wide issues of juvenile unemployment, industrial efficiency and the raising of the school leaving age from which it cannot be divorced without danger to the community.

\title{
The Sanriku (Japan) Earthquake Seawaves of 1933
}

$\mathrm{T}$ HE great earthquake that gave rise to these destructive seawaves occurred on March 3, 1933. As soon as the news of the disaster reached Tokyo, several members of the Earthquake Research Institute were sent to the districts principally affected. The chief points that they investigated were the highest levels reached by the tunami or seawaves, the areas of the regions inundated, the damage to houses, etc., and the relations between the effects of the waves and topographical conditions.

Several memoirs have already appeared and an abstract of one of them, by Messrs. Imamura and Kawase (NATURe, 133, 72-73 ; 1934), gives the main facts as regards the height of the waves and the loss of life and property. In March of the present year, or about a year after the earthquake, the reports of the observers have been published. They occupy a whole volume (Supplementary Vol. I) of the Bulletin of the Earthquake Research Institute. To have produced in so short a time a work of such value and interest, accompanied by such wealth of illustration, is a remarkable feat and one for which seismologists can scarcely be too grateful. The volume contains 521 pages and 251 plates. The first half consists of sixteen memoirs, thirteen of which are written in English and the rest in Japanese with abstracts in English. The second half contains the reports of the observers, which, except for a brief abstract of two pages and the titles of the plates, are written entirely in Japanese.

Besides these investigations, experiments are being made in the Institute laboratory in which, by means of models, the natural conditions are imitated as far as possible. They are still unfinished, but the final results, which will be published shortly by the Institute, can scarcely fail to throw light on the nature of earthquake seawaves.

The tide-tables show that the sea at the time of the earthquake was practically at mean sea-level. The heights reached by the waves were determined from the marks left by them on houses, trees and cliffs. As a rule, the heights reached in 1933 were slightly less than those in 1896 , but some of them were considerable, the greatest being $94 \mathrm{ft}$. at Sirahama in Ryôri.

The propagation of the seawaves is studied by Prof. N. Miyabe (pp. 112-126). They were recorded by mareographs at eighteen stations in Japan, only one of which lies on the Japan Sea side. Unfortunately, the times at which the first waves arrived cannot always be determined with precision, and there may be errors of as much as five minutes in the estimates. Taking their probable values and using the formula $v=\sqrt{ }(g h)$, Prof. Miyabe has drawn circles with the stations as centres, and radii equal to the distances the waves would travel in the intervals between the time of the earthquake and the times of arrival at the respective stations. These circles do not intersect in a point, but envelop one side of an area about $600 \mathrm{~km}$. in length from north to south. Thus, it is possible that the displacement that gave rise to the seawaves may have been several hundred miles in length. The seawaves were also recorded by mareographs at Honolulu, San Francisco and Santa Monica (Cal.). The mareograms at Manila and Wellington (N.Z.) show no trace of the waves, perhaps on account of the disturbing effect of intermediate islands. Nor do those at Sydney and Melbourne record them with certainty. On the other hand, they are shown with considerable amplitude at Iquique in Chile, though that station is nearly 9,000 miles from the origin.

Mr. K. Musya describes in great detail the luminous phenomena observed with the seawaves (pp. 87-111). $\mathrm{He}$ classifies them according to the following types: the crest of the waves emitted dim continuous light (for Prof. Terada's explanation of this light, see Nature, 133, 73; 1934); the surface of the sea glittered all over; the waves on the shore-line gave out bluish light; when the sea-water receded before the arrival of the great waves, the exposed sea-bed gave out blue light; a luminescent body like a meteor was seen; well-defined round luminous bodies were seen in an incoming wave; a round-shaped luminous body appeared above the sea; and bright light radiated from the sea.
C. Davison. 